\title{
Self-care study in the Iranian medical students based on Islamic thought
}

\author{
Morteza Darabinia ${ }^{1}$, Alimorad Heidari Gorji ${ }^{2}$, Shirzad Gholami *3 \\ ${ }^{1}$ Faculty of Medicine, Mazandaran University of Medical sciences, Sari, Iran \\ ${ }^{2}$ Faculty member of EDC, Mazandaran University of Medical sciences, Sari, Iran \\ ${ }^{3}$ Department of Parasitology and Mycology, Faculty of Medicine, Mazandaran University of Medical sciences, Sari, Iran
}

Received: January 25, 2017

DOI: $10.5430 /$ jnep.v7n9p85
Accepted: April 5, 2017

Online Published: April 18, 2017

URL: https://doi.org/10.5430/jnep.v7n9p85

\begin{abstract}
Objective: This study aimed to investigate Islamic Self-care in Iranian medical students.

Methods: In this descriptive study that was done in 2015, students of the Mazandaran University of Medical Sciences (faculties of health, paramedical, pharmacy, medicine and dentistry) were selected through classified random sampling. Study sample was calculated 269 from 900 students based on Krejcie and Morgan's table. Data gathering was done using demographic and a standardized questionnaire about Islamic Self-care.

Results: In this study, 269 students were entered to study. The mean (SD) score of Stipulation, Meditation, Calculation and Expostulation of students were 9.82 (2.35), 10.04 (2.85), 8.74 (2.65) and 7.64 (2.48) respectively. Results shows that correlation between all the components of the Self-care are positive and significant $(p<.001)$.

Conclusions: It is worthy that further study will be aimed to investigate ways to strengthen it, as well as explaining the benefits of Islamic Self-care among students with the theoretical and practical examples.
\end{abstract}

Key Words: Islamic, Medical students, Self-care, Iran

\section{INTRODUCTION}

Self-care has a valuable position in Islamic teachings for individual training and moving toward perfection. ${ }^{[1,2]}$ Islam provided two main approaches to establish control and monitoring in the Muslim community. One approach is establishing public monitoring and control by Islamic governments and people of the community that is called external monitoring. ${ }^{[3,4]}$ However, before and more than that it emphasizes internal controlling and purposeful auditing of individual's own actions and behaviors that is known as a "spiritual accounting", ${ }^{[5]}$ or in the explanation of some writers, it has been called "self-controlling", ${ }^{[6]}$ or "effective controlling system". ${ }^{[7,8]}$ In Islamic principle, it is emphasized that man must be careful what he does, this means that if he decides to do a good work, he implements this decision soon and if he decides to do a bad work, he gives up this decision soon. ${ }^{[9,10]}$ Quran by explaining, "whether you reveal what is in your hearts or hide it Allah will bring you to account for it", emphasizes on "know that Allah knows what is in your minds, therefore beware of him". ${ }^{[11,12]}$

Therefore, human is as a businessman of next world way that his capital is his life and ego is his helper in this way and he must attain this salvation by learning good morals and leaving bad characters and sins. Islamic self-care through

*Correspondence: Shirzad Gholami; Email: mail.mazums@ gmail.com; Address: Department of Parasitology and Mycology, Faculty of Medicine, Mazandaran University of Medical sciences, Sari, Iran. 
(stipulation, meditation, calculation and expostulation) can be a way for catharsis and moving towards eternal bounty and supreme felicity. ${ }^{[13,14]}$ Stipulation means that a person deal with his/her ego that not going to side of guilt and crime. So will order to him/her self to see the sequel of works. Meditation, which literally means protection, in the Quran and mystical culture means permanent protection and continuous care by seeker on his actions, especially actions by heart. ${ }^{[15]}$ So that he sees all his actions in the presence of God and he knows that God conscious about all of his states. Calculation is that person determine a special time in day to audit his/her ego from all items that person deal with ego. ${ }^{[16]}$ Also expostulation means that after of calculation of ego, if shows he/she is guilty, found that he/she is desire to punishment. ${ }^{[16]}$

Agha Babayi et al. (2012) revealed that students of Isfahan University are in a nearly good position in 4 steps of Self-care and field and level of education impact on self-evaluation level of students, but gender does not affect it. ${ }^{[16]}$ Findings of some researchers indicate that there is no significant relation between the views of male and female students about the factors that damage religious education and gender is ineffective in this attitude. ${ }^{[17]}$ In other studies, ${ }^{[18,19]}$ an important self-controlling predictor was identified in all forms of criminal behavior and delinquency, and gender and age also had no significant relationship with criminal behavior and delinquency. The findings of a study ${ }^{[20]}$ showed a significant inverse relationship between the rate of self-controlling and deviant behaviors and indicates that low self-controlling is the cause of participation in deviant behaviors as in accordance with the general theory of crime, low self-control people are vulnerable against the seductive and tempting moments. ${ }^{[21]}$

Since the Self-care and needs to self-controlling and purposeful auditing of individual's own actions in Islam teachings is so important and can be used and studied as an efficient method for modification of students behavior. But based on available databases, there were no previous publication about this issue in Mazandaran province. Therefore, this study aimed to investigate Islamic Self-care in the student of Mazandaran University of Medical Sciences in academic. These hypotheses were selected for this study: 1) Components of self-care are related with them, 2) Self-care are related with demographic indexes.

\section{Methods}

In this descriptive study that was done in 2015, students of the Mazandaran University of Medical Sciences (faculties of health, paramedical, pharmacy, medicine and dentistry) were selected through classified random sampling. Study sample was calculated 269 from 900 students based on Krejcie and
Morgan’s table. ${ }^{[22]}$

\subsection{Criterias}

The inclusion criteria were (i) the desire of students to participate in this research, (ii) having mental and physical health (assessed by self-reporting). Data were collected in a single session using a survey administered in paper-and-pencil format. Participants provided informed consent and dropped completed questionnaires through a slit into an enclosed box. Debriefing forms were given to participants as they exited the classroom. The institutional review board approved the research prior to implementation of the study.

Data gathering was done using demographic and a standardized questionnaire. A standardized questionnaire with 20 questions $^{[16]}$ was used in 2012 to assess students' Self-care. The questionnaire has two main parts of demographic data and the second part in the form of 20 statements includes 4 main components of Stipulation, Calculation, Meditation and Expostulation (Stipulation, questions 1 to 5-Calculation, questions 6 to 10-Meditation, questions 11 to 15 and Expostulation, questions 16 to 20), which were set based on five-point Likert scale (from strongly agree to strongly disagree). The score range was between 0 to 80 . Based on cut point, scores between 0-20, 20.01-40, 40.01-60, 60.01-80 show bad, intermediate, good and well levels of Islamic selfcare respectively. ${ }^{[16]}$ The questionnaire, which was originally designed in the form of 25 questions after the initial study and determining the validity and reliability was reduced to 20 questions and in the final analysis, the number of questions was reduced to 19 . Its validity was confirmed through the content validity. The questionnaire was distributed to 15 experts of associate university of medical sciences. After the necessary modifications the validity was approved. To determine the reliability of the components of the questionnaire, the Cronbach's alpha was used. The reliability of the Self-care questionnaire was estimated $0.94 \%$. After of data gathering, the dada were entered to SPSS data program without identification.

\subsection{Statistical analysis}

Statistical analysis was performed using SPSS software (version 16.0, SPSS Inc., Chicago, IL, USA). KolmogorovSmirnov test was used to assess the normal distribution of quantitative data. Descriptive and infernal statistic tests (analysis of variance, $t$-test and regression) were used. The statistical significant level of all tests was considered as less than .05 .

\subsection{Ethical consideration}

The present study was approved by the ethics committee of the associated university in 2015. Students were informed 
of the study aims and procedures, and that participation was voluntary an informed consent form. To ensure that a broad cross-section of students were allowed to participate in the study, a research assistant who was part of the study team provided support when needed. All personal data were deidentified by assigning codes to the participants.

\section{RESULTS}

In this study, 269 students were entered to study. Demographic profile of participants was shown as Table 1.

Table 1. Demographic profile of participants $(\mathrm{N}=269)$

\begin{tabular}{ll}
\hline Characteristic & N (\%) \\
\hline Gender & $87(32.34)$ \\
Male & $182(67.66)$ \\
Female & \\
Faculty & $47(17.5)$ \\
Health Sciences & $101(37.5)$ \\
Paramedical & $23(8.5)$ \\
Pharmacology & $45(16.8)$ \\
Medical sciences & $33(12.2)$ \\
Nursing and Midwifery & $20(7.5)$ \\
Dentistry Medicine & \\
Education of Father & $57(21.2)$ \\
Elementary & $24(9)$ \\
High School & $86(31.9)$ \\
Diploma & $61(22.6)$ \\
Bachelor & $41(15.3)$ \\
Master and Higher & \\
Education of Mother & $76(28.2)$ \\
Elementary & $25(9.3)$ \\
High School & $98(36.4)$ \\
Diploma & $53(19.8)$ \\
Bachelor & $17(6.3)$ \\
Master and Higher & Mean (SD) \\
Characteristic & $25.67(1.98)$ \\
Age &
\end{tabular}

The mean (SD) scores of Stipulation, Meditation, Calculation and Expostulation of students were 9.82 (2.35), 10.04 (2.85), $8.74(2.65)$ and $7.64(2.48)$ respectively. Also the total score was 36.26 (8.27). Table 2 described the mean score of Self-care based on each faculty. Based on the anal- ysis of variance, the average of components of stipulation, meditation, calculated and expostulation shows a significant difference $(p<.05)$ among different faculties. The obtained results show that the largest number is related with the age. Table 3 shows that correlation between all the components of the Self-care are positive and significant $(p<.001)$.

Among mentioned demographic features, according to Table 4 , only age and faculty have a significant relationship with the Self-care $(p<.05)$ and there was no significant relationship in other factors.

The average of Self-care of men was more than women, but because of the small difference, there was statistically no significant difference. Islamic Self-care was significantly associated with age and the older persons have greater Self-care scores. Increasing the level of education of parents causes better Self-care of students so that students whose parents are educated in Master's degree or higher, had the higher Self-care score, but as the difference was small, there was no statistically significant.

\section{Discussion}

According of the results in present study, the mean of Selfcare and its components among students shows less than mean. In the study of Aliverdinia and Salehnezhad (2011), ${ }^{[20]}$ $60 \%$ of the students at the University of Urmia showed moderate self-controlling and $30.2 \%$ of them were reported high levels. Agha Babayi et al. (2012) ${ }^{[16]}$ in a study were revealed that all the components of Self-care in the students were higher than average that results of both studies are not in accordance with our research. The probable reason may due to differences in study samples, cultural differences of students and methods between studies. However, in the expostulation component, which is corresponding to reprimanding and blaming the ego, the students despite believe in the wrong nature of the action, refuse reprimand and punishment of ego. And this may undermine the positive effects of the stipulation, meditation and calculate. The results of our study are also not in accordance with a study. ${ }^{[23]}$

Table 2. The mean of Islamic Self-care and its components in medical student with regard to the Faculty $(\mathrm{N}=269)$

\begin{tabular}{|c|c|c|c|c|c|}
\hline Faculty & $\begin{array}{l}\text { Expostulation } \\
\text { Mean (SD) }\end{array}$ & $\begin{array}{l}\text { Calculation } \\
\text { Mean (SD) }\end{array}$ & $\begin{array}{l}\text { Meditation } \\
\text { Mean (SD) }\end{array}$ & $\begin{array}{l}\text { Stipulation } \\
\text { Mean (SD) }\end{array}$ & $\begin{array}{l}\text { Total Self-care } \\
\text { Mean (SD) }\end{array}$ \\
\hline Health Science & $8.95(2.36)$ & $8.63(2.30)$ & $7.46(1.81)$ & $7.02(2.06)$ & $32.08(6.23)$ \\
\hline Paramedical & $9.47(2.18)$ & 2.72 (9.99) & $8.42(2.46)$ & 7.33 (2.39) & $35.22(7.76)$ \\
\hline Pharmacology & $10.71(2.30)$ & $11.26(3.28)$ & $10.06(3.25)$ & $8.15(2.87)$ & $40.20(9.42)$ \\
\hline Medical sciences & 9.09 (2.05) & $10.24(2.44)$ & $8.78(2.07)$ & 7.75 (1.83) & $36.69(6.43)$ \\
\hline Nursing and Midwifery & $10.21(2.61)$ & $9.91(3.11)$ & $9.13(3.2)$ & $8.13(2.73)$ & $37.39(9.97)$ \\
\hline$P$-value & $* .000$ & $* .001$ & $* .000$ & $* * .043$ & $* .000$ \\
\hline
\end{tabular}

*p-value $<.001 ; * * p$-value $<.05$ 
Table 3. Correlation between Islamic Self-care components of medical students $(\mathrm{N}=269)$

\begin{tabular}{lllll}
\hline Component & Stipulation & Meditation & Calculation & Expostulation \\
\hline Stipulation & 1 & - & - & - \\
Meditation & .576 & 1 & - & - \\
Calculation & $* .476$ & .547 & 1 & - \\
Expostulation & $* .469$ & $* .478$ & .580 & 1 \\
\hline
\end{tabular}

$* p$-value $<.05$

Table 4. Regression analysis of correlation between Islamic Self-care of medical students and demographic characteristics $(\mathrm{N}=269)$

\begin{tabular}{llllll}
\hline Model & B & Standard Error & Standardized $\boldsymbol{\beta}$ & $\boldsymbol{t}$ & $\boldsymbol{p}$-value \\
\hline Constant value & 31.23 & 2.86 & - & 10.17 & $* .000$ \\
Gender & -1.46 & 1.70 & -0.065 & -1.06 & .287 \\
Age & 0.15 & 0.07 & -0.14 & -2.18 & $* .03$ \\
Faculty & 0.7 & 0.43 & 0.13 & 1.7 & $* .04$ \\
Education of father & 0.096 & 0.478 & 0.015 & 0.20 & .841 \\
Education of mother & 0.508 & 0.540 & 0.077 & 0.94 & .348 \\
\hline
\end{tabular}

${ }^{*} p$-value $<.01$

In present study correlation between all the components of the Self-care was positive and significant. However, the highest correlation was between the components of calculation and expostulation with a value of 0.580 and lowest correlation was between the components of stipulation and expostulation with a value of 0.469 that was in accordance with the outcome of Agha Babayi et al. (2012). ${ }^{[16]}$ This finding indicates that whatever the students are serious for Self-care, such as devoting time for auditing, belief in accounting in the day of resurrection, belief in self-audit before assessing by others, they further tend to expostulation, which means blaming and punishing traitor ego and whatever this assessment is poor in students, the soul addicts to betray with no blaming and no resistance against the ego.

In our study, regression model shows that there is a significant relationship between Islamic Self-care with age and different faculties, but no significant relation was founded between the education of parents and other demographic characteristics such as sex. In the study of Aliverdinia and Salehnezhad (2011), no fundamental and significant difference between two genders of male and female was reported, though self-controlling of girls was a little more than boys. ${ }^{[20]}$ However, in the study of Agha Babayi et al. (2012) the mean of Self-care score of women was more than men, and women were more likely to Self-care that was inconsistent with our results. ${ }^{[16]}$ Hope (2014) in his study concluded that there is no significant relationship between occupation and education of parents and religious attitude, but there is a significant relationship between cost and income and religious attitude that is in accordance with the result of current study. ${ }^{[24]}$

\section{Study limitations}

The most important limitations of presents study were (i) inability to control the emotions and cultural differences of participants, and (ii) careless of participant during filling of questionnaire. So recommended that future study be done with larger sample size to decrease the effect of confounder factors.

\section{Conclusion}

According to results, Islamic Self-care score for most of medical students were less than mean. The relationship among age, field and level of education with the Islamic Self-care compared with other demographic characteristics was also proved. It is worthy that further study will be aimed to investigate ways to strengthen it, as well as explaining the benefits of Islamic Self-care among students with the theoretical and practical examples. Moreover, since the expostulation component (reprimanding and blaming ego for doing bad actions) had the lowest self-care scores, it shown the necessity of more attention for strengthening the students to react timely against the self.

\section{ACKNOWLEDGEMENTS}

We acknowledge to all of the students who help us to complete the study. Also we appreciate the research deputy of Mazandaran University of Medical sciences for their financial support.

\section{CONFLicts OF InTEREST Disclosure}

The authors declare that there is no conflict of interest. 


\section{REFERENCES}

[1] Hashim J. Islamic revival in human resource management practices among selected Islamic organisations in Malaysia. International Journal of Islamic and Middle Eastern Finance and Management. 2009; 2: 251-67. https://doi.org/10.1108/17538390910986362

[2] Alimohammadi N, Taleghani F, Mohammadi E, et al. The nursing metaparadigm concept of human being in Islamic thought. Nursing Inquiry. 2014; 21: 121-9. PMid:23786534 https ://doi .org/10 $.1111 /$ nin. 12040

[3] Jouili JS. Beyond emancipation: subjectivities and ethics among women in Europe's Islamic revival communities. Feminist Review. 2011; 98: 47-64. https://doi.org/10.1057/fr. 2011.4

[4] March AF. Modern Islamic Thought in a Radical Age: Religious Authority and Internal Criticism. By ZamanMuhammad Qasim. Cambridge: Cambridge University Press, 2012. 363p. Perspectives on Politics. 2014; 12: 906-7. https://doi.org/10.1017/S15375 92714002849

[5] Roysircar G. Cultural Self-Awareness Assessment: Practice Examples From Psychology Training. Professional Psychology: Research and Practice. 2004; 35: 658-66. https://doi.org/10.1037/07 $35-7028.35 .6 .658$

[6] Barkaoui K, Couvreur JM, Dutheillet C. On liveness in Extended Non Self-Controlling Nets. In: De Michelis G, Diaz M, editors. Application and Theory of Petri Nets 1995: 16th International Conference Turin, Italy, June 26-30, 1995 Proceedings. Berlin, Heidelberg: Springer Berlin Heidelberg; 1995. p. 25-44. https: //doi.org/10.1007/3-540-60029-9_32

[7] Kuhl J, Quirin M, Koole SL. Being Someone: The Integrated Self as a Neuropsychological System. Social and Personality Psychology Compass. 2015; 9: 115-32. https : //doi.org/10.1111/spc3.1 2162

[8] Heidari Gorji AM, Darabinia M, Ranjbar M. Relationship Between Emotional Intelligence and Job Motivation Among Faculty Staff in Mazandaran University of Medical Sciences, Iran. Iranian Journal of Psychiatry and Behavioral Sciences; In Press: e8065.

[9] Velayutham S. "Conventional" accounting vs "Islamic" accounting: the debate revisited. Journal of Islamic Accounting and Business Research. 2014; 5: 126-41. https ://doi.org/10.1108/JIABR-0 5-2012-0026

[10] Hosseini Ashlaghi M, Heidari Gorji AM, Darabinia M, et al. Impact of suggestions system on the employee performance in Mazandaran University of Medical Sciences. International Journal of Humanities and Cultural Studies (IJHCS). 2016. 1370-83.

[11] Shabana A. LAW AND ETHICS IN ISLAMIC BIOETHICS: NONMALEFICENCE IN ISLAMIC PATERNITY REGULATIONS. Zy- gon. 2013; 48: 709-31. https://doi.org/10.1111/zygo.120 41

[12] Hoover J. Free Will and Predestination in Islamic Thought: Theoretical Compromises in the Works of Avicenna, al-Ghazali and Ibn Arabi. Islam and Christian-Muslim Relations. 2015; 26: 516-8. https://doi.org/10.1080/09596410.2015.1053274

[13] Hassi A. Islamic perspectives on training and professional development. Journal of Management Development. 2012; 31: 1035-45. https ://doi.org/10.1108/02621711211281816

[14] Todd R. Universality in Islamic Thought: Rationalism, Science and Religious Belief. Islam and Christian-Muslim Relations. 2016; 27 535-8. https://doi .org/10.1080/09596410.2016.1205828

[15] Drake SC. A Meditation on the Soundscapes of Black Boyhood and Disruptive Imaginations. Souls. 2016; 18: 446-58. https: //doi.org/10.1080/10999949.2016.1230827

[16] Agha Babayi R, Nasr Isfahani AR, Rahimi H. Level of Islamic selfassessment in students of Isfahan University. Education Strategies in Medical Sciences. 2012; 5: 119-24.

[17] Hosseinzadeh OA, Musharefi H. Factor analysis of damaging factors of religious training of students of Islamic Azad University. Woman and Family Studies. 2010; 2: 41-60.

[18] Isralowitz R, Reznik A. Impact of Religious Education and Religiosity on Adolescent Alcohol Use and Risk-Taking Behavior. Religious Education. 2015; 110: 303-10. https ://doi .org/10.1080/0034 4087.2015 .1039388

[19] Bayim CO. Religious Education for the Deescalation of Communal Conflicts in Boki Land, Nigeria. Religious Education. 2015; 110: 29-51. https://doi.org/10.1080/00344087.2015.989095

[20] Aliverdinia A, Salehnezhad S. Self-controlling, gender and its effects on deviant behaviors. Women in Development and Policy. 2011; 9 : 16.

[21] Fescioglu-Unver N, Kokar MM. Self Controlling Tabu Search algorithm for the Quadratic Assignment Problem. Computers \& Industrial Engineering. 2011; 60: 310-9. https://doi.org/10.1016/j.ci e.2010.11.014

[22] Chuan CL. Sample size estimation using Krejcie and Morgan and Cohen statistical power analysis: A comparison. Jurnal Penyelidikan IPBL. 2006; 7: 78-86.

[23] Carey JM, Paulhus DL. Worldview Implications of Believing in Free Will and/or Determinism: Politics, Morality, and Punitiveness. Journal of Personality. 2013; 81: 130-41. PMid:22812486 https ://doi.org/10.1111/j.1467-6494.2012.00799.x

[24] Hope ALB, Jones CR. The impact of religious faith on attitudes to environmental issues and Carbon Capture and Storage (CCS) technologies: A mixed methods study. Technology in Society. 2014; 38: 48-59. https://doi.org/10.1016/j.techsoc. 2014.02.003 